\title{
Exploring the relationship between HIV and alcohol use in a remote Namibian mining community
}

NOTICE: This is the authors version of a work that was accepted for publication in African Journal of AIDS Research. Changes resulting from the publishing process, such as peer review, editing, corrections, structural formatting, and other quality control mechanisms, may not be reflected in this document. Changes may have been made to this work since it was submitted for publication. A definitive version was subsequently published in African Journal of AIDS Research.

Citation:

Lightfoot, E., Maree, M. \& *Ananias, J. (2009). Exploring the relationship between HIV and alcohol use in a remote Namibian mining community. African Journal of AIDS Research, 8(3): 321-327.

\begin{abstract}
In southern Africa, the use of alcohol is increasingly seen as creating a context of risk for HIV transmission. This qualitative study investigates the links between alcohol use and higher-risk sexual behaviours in a remote southern Namibian mining-town community. Using data from six focus groups and 16 in-depth interviews conducted in 2008, the researchers investigated knowledge of the link between alcohol consumption and HIV risk, focusing on the specific mechanisms related to drinking and higher-risk sexual behaviours. Although knowledge regarding HIV and alcohol was high among the mineworkers and other community members, the social structure of a remote mining town appears to lead to high levels of alcohol use and higher-risk sexual behaviours. The heavy use of alcohol acts as an accelerant to these behaviours, including as a source of fortitude for those with an intention to engage in casual sexual partnerships or multiple concurrent partnerships, and as a cause for those behaviours for people who may otherwise intend to avoid them. The findings suggest a need for HIV-prevention programmes that focus more holistically on HIV and AIDS and alcohol use, as well as the need for structural changes to mining-town communities in order to reduce the likelihood of both heavy alcohol use as well as a high prevalence of higher-risk sexual behaviours.
\end{abstract}

Keywords: community profiles, HIV/AIDS, mineworkers, prevention, risk behaviour, risk factors, sexual behaviour, southern Africa.

\section{Introduction}

HIV and AIDS is a critical issue in sub-Saharan Africa, and the southern African nation of Namibia has one of the highest levels of HIV prevalence in the world, with approximately $19.6 \%$ of Namibian adults living with HIV (UNAIDS, 2006). High levels of HIV prevalence have drawn much attention to HIV-related research, prevention and intervention efforts across the region. In developing appropriate HIV-prevention programmes in countries with high rates of HIV infection, it is important to understand the factors leading to HIV transmission. An important HIV-risk factor currently receiving attention in sub-Saharan Africa is the role of alcohol use in the spread of HIV. As alcohol use is exceptionally high among migratory mineworkers in general, this study 
looks at the connection between alcohol use and HIV transmission among people living in a remote mining town in southern Namibia.

Alcohol use is relatively high in southern African countries, including Namibia (Social Impact Assessment and Policy Analysis Corporation [SIAPAC], 2002). Namibians consume both bottled alcohol, such as beer and whiskey, and traditional, home-brewed drinks, such as mataku, walende or oshikundu. While the World Health Organization (WHO) (2004) has officially reported alcohol consumption in Namibia as moderately high, with adults on average consuming just over two litres of alcohol weekly, these reports are likely artificially low. For instance, the WHO statistics do not include the consumption of home-brewed alcohol, which may account for roughly two-thirds of alcohol consumed in Namibia (Mustonen, Beukes \& DuPreez, 2001). A comprehensive, nationwide survey by SIAPAC (2002) found that 55\% of Namibian adults consumed more than 10 litres of alcohol per week, and a study of Namibian schoolchildren found that alcohol use was also high among adolescents; data from WHO showed that $43 \%$ of Namibian schoolchildren aged 13 to 17 years were regular drinkers of alcohol (Chinsembu, Siziya, Muula \& Rudatsikira, 2008).

The link between alcohol use and HIV in sub-Saharan African nations with high HIV prevalence has been receiving growing attention from researchers and health professionals. A number of studies have found alcohol consumption to be a risk factor for HIV. For example, alcohol has been linked as a risk factor for acquiring HIV in Tanzania (Mnyika, Klepp, Kvale \& Ole-Kingori, 1997; Kapiga, Lyamuya, Lwihula \& Hunter, 1998), Kenya (Hargreaves, Morison, Chege, Rutenburg, Kahindo \& Weiss, 2002), Uganda (Mbulaiteye, Ruberantwari, Nakiyingi, Carpenter, Kamali \& Whitworth, 2000), Zambia (Morrison, Sunkutu, Musaba \& Glover, 1997), and South Africa (Zuma, Gouws, Williams \& Lurie, 2003). However, to date, most findings that link HIV risk and alcohol use in sub-Saharan African populations have been from studies not specifically designed to focus on the relationship of alcohol use to HIV transmission, thus the measures relating to this topic have been imprecise (Kalichman, Simbayi, Kaufman, Cain \& Jooste, 2007).

A few studies have looked more directly at the associations between alcohol consumption and HIV. For example, in a population study in Rakai, Uganda, Zablotska, Gray, Serwadda, Nalugoda, Kogozi, Sewankambo et al. (2006) found that the consumption of alcohol before sex increased the likelihood that individuals would acquire HIV. Likewise, Fritz, Woelk, Bassett, McFarland, Routh, Tobaiwa \& Stall (2002) found that Zimbabwean beerhall patrons who had sex while intoxicated were much more likely to acquire HIV. In a qualitative study of alcohol users in Gauteng Province, South Africa, Morojele, Kachienga, Mokoko, Nkoko, Parry, Nkowane et al. (2006) found that most drinkers felt that there was a strong link between alcohol use and higherrisk sexual behaviours. Other studies have begun to examine the specific mechanisms relating to how alcohol use can lead to instances of HIV transmission. For example, a qualitative study in South Africa (Simbayi, Mwaba \& Kalichman, 2006) found that alcohol lowered sexual inhibitions, led to transactional sex and created barriers to using condoms. In addition, in a study of South African men who were given free condoms, Myer (2002) found that those who used alcohol were less likely to actually use the condoms. Likewise, in a qualitative study of people living in rural Ghana, Luginaah (2008) found that consumption of locally brewed alcohol could be associated with higher risk factors for HIV, such as coercive sex and violence. However, little research has 
been done in southern Africa regarding the mechanisms that account for an association between alcohol use and sexual risk-taking (Kalichman et al., 2007), including how the link plays out in specific settings unique to southern Africa.

One area where the link between increased instances of HIV transmission and alcohol use that has not been extensively studied is among mining-town communities. Mining is one of the largest economic sectors in southern Africa; there are large mines in South Africa, Botswana, Namibia, Zambia and Mozambique, which harvest gold, diamonds, zinc, lead, copper, uranium and other minerals and gems. Many of the mineworkers migrate large distances to reach the mines, returning home to visit their families as little as once a year. Migrant workers in the mining industry are thought to be at very high risk of exposure to HIV (Campbell, 1997; Desmond, Allen, Clift, Justine, Mzugu, Plummer et al., 2005), partly because of the migratory nature of their employment and because living so far from their family may lead them to have multiple concurrent sexual partnerships or to pay for sex (Desmond et al., 2005).

Previous studies have found that alcohol use tends to be extremely high among mineworkers in southern Africa (e.g. Michalowsky, Wicht \& Moller, 1989; Heywood, 1996; Pick et al., 2003). As there is a high rate of alcohol consumption among mineworkers, alcohol use may be one of the mechanisms leading to increased risk of exposure to HIV. Several studies have pointed to a link between new HIV infections and alcohol use in mining towns (e.g. Campbell, Williams \& Gilgen, 2000; Mbulaiteye et al., 2000; Clift, Anemona, Watson-Jones, Kanga, Ndeki, Changalucha et al., 2003); however, no studies have examined this directly from the perspective of those living in a mining town. Because mineworkers as a group are associated with high levels of alcohol use and higher-risk sexual behaviours, understanding the relationship between HIV and alcohol use among those living in mining towns is imperative for designing appropriate interventions for these locations.

The research questions investigated for this study were: 1) What is the level of knowledge regarding the link between HIV and alcohol use among people living in a remote mining town? 2) What mechanisms affect how alcohol consumption leads to higher-risk sexual behaviours among people living in a remote mining town?

\section{Research setting}

The specific context for the inquiry was a remote mining town in southern Namibia, a sparsely populated desert region. The mining company had established the town, which had approximately 10000 inhabitants ( 3500 working for the mine) at the time of the study, and it controlled much of the towns operations. Virtually all the workers came from regions hundreds of kilometers away from the mining town, with the majority of the workers hailing from Ovamboland in northern Namibia, roughly $1500 \mathrm{~km}$ north of the town, with a substantial portion of that on gravel roads. The mining town is a closed town located in a large region that requires a government-issued permit for entrance, and where frontline workers are not allowed to have family living with them in the town. Many of the workers live in dormitories. The main forms of entertainment in town are sports clubs and local informal entertainment establishments, consisting primarily of approximately 200 shebeens. 
The mining company provides comprehensive medical care for all workers, including antiretroviral drugs (ARVs) for workers with HIV infection, and it provides information regarding HIV to its employees on a regular basis. According to a source at the mine (personal communication, 2008), prevalence at the time of the study was about $9 \%$ among the workers employed there, relatively low for Namibia. However, this estimate might have been artificially low as it only included workers currently employed at the mine, not those who might have stopped working due to illness.

\section{Sample}

\section{Methods}

The study used a qualitative approach to gather in-depth information about the link between HIV transmission and alcohol use among people living in a remote mining community in Namibia. This was part of a larger study examining substance use in this particular mining community. The study population consisted of the workers, family members and professionals who lived in the mining town. The researchers collected data through six focus group discussions and 16 key informant interviews. Individuals were selected for interviews based on their job category, such as doctor, church leader or human resources professional. The focus groups included groups of supervisors/foremen, mineworkers, Oshiwambo-speaking workers, workers who had undergone treatment for substance abuse, workers spouses, and youths (ages 1720 years) who had grown up in the town. In total, 46 people participated in the focus groups, including participants whose first language was Oshiwambo, Afrikaans or German. A social worker working for the large mining company in the community facilitated recruitment for both the key informant interviews and focus group discussions; the research team determined the categories of the respondents, and the social worker identified and contacted potential participants. While this recruitment method had the risk of selection bias (and certainly potential participants might not have been included), this was the only means of accessing participants at this closed site.

\section{Data collection}

The qualitative data were collected during the first week of June 2008. At least three of the four members of the research team were present at all the interviews and focus groups. Most of the interviews and focus groups were conducted in English, the official language of Namibia; however, an Oshiwambo-speaking translator was available for all interviews and focus groups as some participants first language was Oshiwambo, and one focus group was conducted entirely in Oshiwambo. In addition, two of the researchers were fluent in Afrikaans, and portions of some interviews were conducted in Afrikaans for those participants whose first language was Afrikaans. All the interviews and focus groups were held in a private location to assure confidentiality, and all the participants gave formal consent for participation in this study. For each interview and focus group, there was a lead interviewer, a lead note-taker (who used a laptop computer to take notes in English), and at least one additional member of the research team who took notes and asked follow-up questions.

The researchers conducted semi-structured, in-depth interviews with the key informants, with the aid of a structured interview guide, lasting approximately 60 minutes each. The participants were asked to discuss to what extent they felt that people working and living in the mining-town community understood the link between HIV/AIDS and alcohol consumption. For the focus groups, the researchers used a focus-group guide that included general questions about 
the link between HIV and alcohol use. The focus group discussions were scheduled to last 60 minutes each, but some lasted more than 90 minutes.

\section{Data analysis}

The researchers used several methods for analysing the data. First, after each focus group and interview, the research team held debriefing sessions, lasting between 15 and 30 minutes, in order to review the information they had just gathered, to ensure that the translations were appropriate, and to evaluate the process of the particular interview or focus group. Later, the researchers independently reviewed the detailed notes and debriefing forms from each focus group and interview, coding the raw data for key themes. Each researcher developed his or her own themes, and then the team met numerous times to reconcile, collapse and organise the key themes.

\section{Findings}

\section{Knowledge among mineworkers about HIV/AIDS and its link to alcohol use}

The respondents were consistent in describing the level of general knowledge about HIV and AIDS as high among people working in the mine and living in the mining town. As one mineworker said, There is not a thing about HIV that is not known. The respondents repeatedly praised the mining company for providing comprehensive information about HIV and AIDS to mineworkers and for providing appropriate treatment to company employees living with HIV. However, there were concerns that the HIV/AIDS education provided by the company did not stress the risks of drinking for acquiring or transmitting HIV. One mineworker said, People are told about drugs and alcohol or HIV/AIDS or peer pressure, but never a link together between these things.

While knowledge about HIV and AIDS was universally reported as high, there was less consensus about whether people working in the mine at large truly understood the link between substance use and the risk of HIV infection or transmission. Several respondents indicated that some mineworkers did not truly understand this link. Other respondents indicated that while most people were aware that substance use can lead to engaging in higher-risk sexual behaviours, they did not apply that knowledge. One mineworker said, I think they have an idea of the dangers, but they use poor judgment and have poor decision-making when they are under the influence. It affects their decisions. Some respondents said that when mineworkers consumed alcohol, they were more likely to engage in higher-risk sexual behaviour, such as having sex without a condom, having sex concurrently with more than one partner, or having sex with people they knew had multiple, concurrent partners.

Mechanisms related to alcohol use and leading to higher-risk sexual behaviour

Comments made in the focus groups and interviews illuminated the mechanisms related to alcohol use that could lead to higher-risk sexual behaviour among the mineworkers. The mineworkers and other community members reported living in an environment that can lead both to a high level of alcohol use and higher-risk sexual behaviour. Additionally, their comments suggested that the high level of alcohol use can further contributes to higher-risk sexual behaviour among the workers.

\section{Factors leading to alcohol use among the mineworkers}


The respondents described many factors leading to alcohol use among mineworkers. While the factors leading to the use of substances are many and varied, they seem to generally stem from the structure of the mining workforce, which relies on many male migrant workers who must live far away from their families, in hostels, and in a remote location. Respondents said many mineworkers were bored and lonely living far away from their families and working unusual shift schedules, sometimes sharing a hostel room with a stranger for years, and finding nothing to do in the mining town aside from drinking. As the mineworkers made a decent salary, they also had ample money to spend on alcohol.

\section{Migrant workers miss their families}

A common theme in the focus groups and interviews related to migrant workers living away from their families. The respondents repeatedly mentioned this as a primary cause of the high levels of substance abuse among workers, particularly older workers who had families living in northern Namibia. The respondents talked about how they missed their own families, and said that many other workers felt similarly. Many respondents reported a direct link between missing their families in the north and the high rate of substance abuse:

I am a northerner. My mind is always outside. At the end of the day, you feel more of a stranger. Every now and then you think of other jobs. You think, I am not here to stay. I am soon to be leaving (mineworker).

Myself, I am very far away from the north. My wife is not here. My family is not here. Everything is far away. It s stressful (mineworker).

Their families are far away from them. It is not easy to talk over the distance. They aren $t$ home to solve the problems (mineworker).

They are working here, but their family members are in the north. Sometimes they used to say I have to take something to drink just to forget there is someone there at home (community member).

\section{Loneliness}

A second theme relating directly to that of missing ones family was a pervasive sense of loneliness among the workers who lived a long distance from their families and villages. This caused workers to turn to alcohol to fill the void in their lives. One mineworker said, People are looking for things to vent their frustrations of loneliness. Another said: Most of them are not youngsters. They leave their family behind in the north. It $s$ quite difficult visiting your families. You can take three weeks per year. You don $t$ know what to do with yourselves. So you get together, and have a drink or two. They go to the [local drinking establishment], or the Cuca shops. It s nice. You don $t$ feel lonely.

\section{Boredom}

Coupled with missing their families and feeling lonely, people working in the mine also indicated that the extreme boredom associated with living in a remote mining town also led to high levels of alcohol use. Most respondents said that the town had limited entertainment to appeal to the majority of workers. The combination of living away from ones family without entertainment options contributed to a sense of boredom. The respondents indicated that people drank alcohol to relieve their boredom as one young mineworker described, there was nothing to do but party, party and drink, drink. 
Spending money

Most respondents reported that mineworkers made a decent salary compared to other people in Namibia, and that they had limited expenses when living in a hostel. Although the mineworkers may have been supporting a family or house in another part of the country, they did not necessarily see those expenses as immediate. Thus, many respondents indicated that because workers have money that looks like disposable income in the short-term, they are likely to spend this money on alcohol. One community member said, Here we have too much money. In other places, they can only buy one or two [drinks]. Here they can buy ten. A mineworker said, The richer you go, the worse it [drinking] gets.

Gender imbalance

Another structural factor related to increased alcohol use was the imbalance between males and females in the mining town. Males are much more likely than females to be employed in lowerranking mining jobs. This gender imbalance leads to a social scene that revolves primarily around males drinking together, without women or other family members nearby to perhaps help regulate their drinking. Some respondents indicated a socio-cultural norm in Namibia that dictates men are supposed to drink. With so many men together without women around, it is almost inevitable to have high levels of drinking: If their families are around, they don $t$ do that [drink excessively] (mineworker).

\section{Interactions between alcohol use and living in a remote mining community}

Some of the same factors that lead to alcohol use among those living in the mining community may also lead to higher-risk sexual behaviours, such as having multiple partners or not practicing safer sex. The respondents indicated that heavy alcohol use in the mining town community acted as an accelerant to higher-risk sexual behaviours. The following sections describe the themes most commonly emerging from the interviews and focus groups.

Mineworkers seeking partners in town

As many mineworkers may live away from their spouses for years, some will seek another sex partner in town. Thus, many respondents comments that mineworkers often have at least one other sexual partner in addition to their wives that live a long distance away. And, as one mineworker explained: Some people like alcohol to meet women.

Gender imbalance leads to sharing partners

As mentioned above, the gender ratio was very imbalanced in the mining community. Thus, the women living in the mining town tended to have multiple, concurrent partners. One community member said, [Women] are always in the company of more than one male. You never see equal groups. The occurrence of multiple, concurrent partners can lead to the transmission of HIV. One mineworker pointed out this was the nature of the mining town: [There are] more males than females. People start sharing partners. That $s$ where the spreading [of HIV] comes in.

While the respondents indicated that most mineworkers understood the risk inherent in having sex with a person who has multiple concurrent partners, the respondents mentioned male mineworkers using alcohol as a means to forget about the risk. Respondents said that men often used alcohol as a way to gain the courage to talk with one of the few women in town. One mineworker described this situation: Then there are only a few ladies in the area you have to 
live with the fear that you are not only the person dating that person. I 11 wait until the weekend and go drink, and then go find the girl.

Sex work

While the towns police records did not document any instances of prostitution, some respondents described sex work as rampant and closely tied to alcohol consumption, the structure of the mining workforce, and the resulting gender imbalance in town. Respondents related how male mineworkers are almost always drinking when they hire prostitutes, implying that when they are sober they are aware that this is a risky behaviour. One mineworker described how alcohol led mineworkers to visit prostitutes: [Mineworkers] look for artificial courage to do those things.

Another described drinking as leading to behaviours that a person might otherwise think are immoral, such as adultery or prostitution, and which they might later lament: Whenever you are under the influence of alcohol, you do something, you don $t$ do what you want to do. You might regret it later.

The respondents also discussed how alcohol leads women in town to be involved in sex work. This was described as both formal prostitution in town, meaning that women came to town to make money from sex work, and informal prostitution, which most often happened on an impromptu basis. The respondents described formal prostitution as managed from the drinking establishments in town, with some operating as brothels. Impromptu prostitution was usually described as heavily related to alcohol use: After she is drinking, she says if you give me a certain amount of money, I will go with you (community member).

\section{Alcohol reduces use of condoms}

A prevalent theme throughout nearly all the focus groups and interviews was how alcohol frequently leads to the misuse or nonuse of condoms, which is particularly risky in the community context of a high prevalence of multiple, concurrent partners and sex work. While many respondents indicated that the knowledge of safer sex and the importance of condom use was nearly universal among people in this community, the use of alcohol caused people not to apply this knowledge. For example, one community member said, If you are sober, you might be responsible use a condom but if you are under the alcohol, you don $t$ even think about using a condom. Similarly, another indicated, If you are drunk, even if you have a condom, you have no idea where your condom went. Finally, a mineworker said, When you drink, you don thave control over yourself. The girl is beautiful, so you don think of using a condom or using it properly.

\section{Discussion}

The qualitative research reveals that the mineworkers and other community residents in a remote mining town in southern Namibia well understood how HIV is transmitted and also how heavy use of alcohol could lead them to risky sexual behaviour. The mineworkers and others living in the town had a general awareness of the link between alcohol consumption and increased risk of HIV; however, this knowledge did not typically lead to behaviour change regarding alcohol use or engagement in higher-risk sexual behaviour. In addition, the training and outreach efforts provided to the mineworkers seemed not to emphasize the link between alcohol consumption and HIV risk. Thus, while ample information about HIV and AIDS and the use alcohol was available to the mineworkers, they were not taught about the associated risks in a holistic fashion. 
The findings of this qualitative study, the first on this topic in Namibia, echo those of other southern African studies regarding the link between alcohol use and HIV transmission. Instead of focusing on correlations between alcohol consumption and HIV acquisition, this study focused on the social mechanism of how alcohol use leads to higher-risk sexual behaviours from the perspective of those living in a remote mining town. As in the studies conducted by Simbayi et al. (2006) and Meyer (2002), this study found that alcohol consumption was linked to lowered sexual inhibitions, an increased likelihood of engaging in commercial or transactional sex, and problems with using condoms. Alcohol use in the mining community was related to higher-risk sexual behaviours in two different ways. On the one hand, the respondents described drinking as an excuse that people used for engaging in higher-risk sexual behaviours or for having multiple sexual partners, as people commonly drank alcohol with the purpose of gaining courage to meet women for sexual relations. Thus, men in the community were not unlikely to consume alcohol as a conscious means of forgetting the risks of having sex with multiple partners or with a woman who has multiple partners. On the other hand, drinking was also described as the cause of higherrisk sexual behaviours, as people who intended to avoid higher-risk sexual partnerships or who intended to use a condom when having sex would forget these intentions after indulging in alcohol. While the study could not distinguish which types of people were likely to use alcohol as an excuse for higher-risk sexual behaviour in comparison to those who engaged in risky sexual behaviour as a result of alcohol use, future studies may be able to shed more light on this distinction. Because the mechanisms fueling HIV-risk behaviours and alcohol consumption may differ between these two groups, understanding the distinction between the groups might lead to more effective health promotion interventions.

The risks of alcohol as an accelerant for higher-risk sexual behaviour for those living alone in a remote mining community may be greater than for those living with their families. The migratory mineworkers in this study described extreme feelings of longing for their families, loneliness and boredom, complicated by an environment with a severe gender imbalance. The respondents indicated that mineworkers used alcohol both as a means for drowning their sorrows, filling up the time, and gaining a sense of camaraderie with fellow workers, as well as a means for meeting and having casual sex with women whom they may suspect had other partners, or for paying for sex. Alcohol consumption was described as a means to gain courage to participate in higher-risk sexual relationships, and also as a primary factor leading to having sex without a condom. Thus, the heavy use of alcohol related to living in a remote mining town combined with the structural nature of the mining community created a context of risk wherein people did not apply their knowledge about HIV transmission. In fact, the social pressures of living in a stressful environment might have been key to why knowledge about HIV was often not put into practice.

There has been new emphasis on multiple, concurrent sexual partnerships as a driver of the HIV epidemic in southern Africa (Morris \& Kretzschmar, 1997; Kelly, Gray, Valente, Sewankambo, Serwadda, Wabwire-Mangen et al., 2000; Halperin \& Epstine, 2004; Shelton, Halperin, Nantulya, Potts, Gayle \& Holmes, 2004). While people in southern Africa may not have a greater number of sexual partners on average than those in other regions, they are more likely to have several, long-term concurrent partners. Even if people tend to have just a few concurrent partners, HIV is still likely to spread rapidly through the sexual networks. The social structure of the labor force in mining communities can lead directly to the largely male population of 
mineworkers and the relatively few females living in the mining town to have multiple, concurrent sexual partnerships. The respondents in this study described drinking as a key factor leading to multiple sexual partnerships and to not using condoms. As other studies have pointed out relatively high levels of alcohol use among mineworkers (Pick et al., 2003); thus, people living in mining towns may be at high risk for spreading HIV through multiple sexual partnerships.

\section{Limitations of the study}

This study provides new information about alcohols effects on HIV-risk behaviour, particularly in Namibia which has received little previous research attention; however, several limitations must be addressed. First, the study relied on data from only one site and involved a limited sample, thus limiting the generalisibility of the findings. Second, the study used data that relied on the perceptions of mineworkers regarding their understanding of the effects of alcohol consumption on HIV incidence. Thus, while the respondents reported having a high level of knowledge about HIV, we were not able to confirm their claims. Third, the recruitment procedures relied extensively on an organisational employee for recruiting the participants, which may have resulted in selection bias of the sample. However, the use of qualitative methods allowed for in-depth discussions with the participants regarding their understanding of the link between alcohol consumption and HIV risk, and thus their comments provide information that can be usefully applied to a more comprehensive investigation.

\section{Conclusions}

HIV-prevention efforts must take into account a relationship between alcohol use and HIV risk, particularly in southern Africa where alcohol consumption is relatively high. This is particularly true for mining communities, where the combination of heavy alcohol use and the structural nature of mining towns creates an environment ripe for multiple, concurrent partnerships. Some mining companies have been progressive in providing HIV/AIDS information and treatment to their employees, as a result of recognising the impact of HIV on their employees health and ultimately on the profitability of their business. While this is commendable, this study points to alcohol use as a specific driver for higher-risk sexual partnerships and behaviours among mineworkers. HIV-prevention programmes should stress the link between drinking and HIV risk in a holistic fashion; companies may want to emphasise the importance of responsible drinking among the workforce as a means to reduce new HIV infections. The findings also suggest the need for structural changes to mining communities, such as providing family accommodation for workers, since information alone may not be enough to change workers behaviour. This is particularly the case for industries that rely on a migratory workforce, as the social structure of such a workforce is a likely cause for both heavy alcohol use and more frequent higher-risk sexual behaviours.

\section{References}

Campbell, C. (1997) Migrancy, masculine identities and AIDS: the psychosocial context of HIV transmission on the South African gold mines. Social Science and Medicine 45(2), pp. 273 281.

Campbell, C., Williams, B. \& Gilgen, D. (2002) Is social capital a useful conceptual tool for exploring community-level influences on HIV infection? An exploratory case study from South Africa. AIDS Care 14(1), pp. 4154. 
Chinsembu, K., Siziya, S., Muula, A. \& Radatsikira, E. (2008) Prevalence and social correlates of sexual intercourse among school-going adolescents in Namibia. SAHARA Journal of Social Aspects of HIV/AIDS Research Alliance 5(3), pp. 129135.

Clift, S., Anemona, A., Watson-Jones, D., Kanga, Z., Ndeki, L., Changalucha, J., Gavyole, A. \& Ross, D.A. (2003) Variations of HIV and STI prevalence within communities neighbouring new goldmines in Tanzania: importance for intervention design. Sexually Transmitted Infections 79, pp. 307312.

Desmond, N., Allen, C., Clift, S., Justine, B., Mzugu, J., Plummer, M., Watson-Jones, D. \& Ross, D. (2005) A typology of groups at risk of HIV/STIs in a goldmining town in north-western Tanzania. Social Science and Medicine 60(8), pp. 17391749.

Fritz, K.E., Woelk, G.B., Bassett, M.T., McFarland, W.C., Routh, J.A., Tobaiwa, O. \& Stall, R.D. (2002) Alcohol use, sexual risk behavior and HIV infection among men attending beerhalls in Harare, Zimbabwe. AIDS and Behavior 6(3), pp. 221228.

Halperin, D. \& Epstine, H. (2004) Concurrent sexual partnerships help to explain Africas high HIV prevalence: implications for prevention. The Lancet 264, pp. 46.

Hargreaves, J.R., Morison, L.A., Chege, J., Rutenburg, N., Kahindo, M. \& Weiss, H.A. (2002) Socioeconomic status and risk of HIV infection in an urban population in Kenya. Tropical Medicine and International Health 7, pp. 793802.

Heywood, M. (1996) Mining industry enters a new era of AIDS prevention. Eyewitness: South Africa. AIDS Annals of Africa 6(3), p. 16.

Kalichman, S., Simbayi, L., Kaufman, M., Cain, D. \& Jooste, S. (2007) Alcohol use and sexual risks for HIV/AIDS in southern Africa: systematic review of empirical findings. Prevention Science 8, pp. 141151.

Kapiga, S., Lyamuya, E., Lwihula, G. \& Hunter, D. (1998) The incidence of HIV infection among women using family-planning methods in Dar es Salaam, Tanzania. AIDS 12(1), pp. 7584.

Kelly, R., Gray, R.H., Valente, T.W., Sewankambo, N.K., Serwadda, D., Wabwire-Mangen, F., Lutalo, T., Li, C. \& Wawer, M.J. (2000) Concurrent and non-concurrent sexual partnerships and risk of prevalent and incident HIV. Paper presented at the International Conference on AIDS, Durban, South Africa, 914 July 2000.

Luginaah, I. (2008) Local gin (akpeteshie) and HIV/AIDS in the Upper West Region of Ghana: the need for preventive health policy. Health and Place 14, pp. 806816.

Mbulaiteye, S.M., Ruberantwari, A., Nakiyingi, J.S., Carpenter, L.M., Kamali, A. \& Whitworth, J.A.G. (2000) Alcohol and HIV: a study among sexually active adults in rural southwest Uganda. International Journal of Epidemiology 29, pp. 911915.

Michalowsky, A., Wicht, C. \& Moller, A. (1989). The psychosocial effects of living in an isolated community: A community health study. SouthAfrican Medical Journal, 75, 532-534.

Mnyika, K.S., Klepp, K.I., Kvale, G. \& Ole-Kingori, N. (1997) Determinants of high-risk sexual behaviour and condom use among adults in the Arusha region, Tanzania. International Journal of STD and AIDS 8(3), pp. 176183.

Morojele, N., Kachienga, M., Mokoko, E., Nkoko, M., Parry, C., Nkowane, A., Moshia, K. \& Saxena, S. (2006) Alcohol use and sexual behaviour among risky drinkers and bar and shebeen patrons in Gauteng Province, South Africa. Social Science and Medicine 62, pp. 217 227.

Morris, M. \& Kretzschmar, M. (1997) Concurrent partnerships and the spread of HIV. AIDS 11, pp. 681683. 
Morrison, C.S., Sunkutu, M.R., Musaba, E. \& Glover, L.H. (1997) Sexually transmitted disease among married Zambian women: the role of male and female sexual behaviour in prevention and management. Genitourinary Medicine 73(6), pp. 555557.

Mustonen, H., Beukes, L. \& DuPreez, V. (2001) Alcohol drinking in Namibia. In: Demers, A., Room, R. \& Bourgault, C. (eds.) Surveys of Drinking Patterns and Problems in Seven Developing Countries. Geneva, World Health Organization (WHO).

Pick, W., Naidoo, S, Ajani, F., Onwukwe, V., Hansia, R. \& Bielu, O. (2003). Prevalence of alcohol and cannabis use and reported knowledge, attitudes and practice regarding its relationship with health and safety on mines in South Africa. Safety in Mines Research Advisory Committee: Wits school of public health, Health 712, Johannesburg, South Africa.

Shelton, J., Halperin, D.T., Nantulya, V., Potts, M., Gayle, H.D. \& Holmes, K.K. (2004) Partner reduction is crucial for balanced ABC approach to HIV prevention. British Medical Journal 328, pp. 891893.

Social Impact Assessment and Policy Analysis Corporation (SIAPAC) (2002) Nationwide KAP Baseline Survey on Alcohol and Drug Use and Abuse in Namibia. Windhoek, Namibia, Ministry of Health and Social Services, and the Ministry of Agriculture, Water and Rural Development.

Simbayi, L.C., Mwaba, K. \& Kalichman, S. (2006) Perceptions of STI clinic attendees about HIV/ AIDS and alcohol as a risk factor with regard to HIV infection in South Africa: implications for HIV prevention. Social Behavior and Personality 34(5), pp. 535543.

UNAIDS (2006) 2006 Report on the Global AIDS Epidemic: A UNAIDS 10th Anniversary Special Edition. New York, UNAIDS.

World Health Organization (2004) Global Status Report on Alcohol, 2004. Geneva, World Health Organization (WHO).

Zablotska, I., Gray, R., Serwadda, D., Nalugoda, F., Kogozi, G., Sewankambo, N., Lutalo, T., Mangen, F. \& Wawer, M. (2006) Alcohol use before sex and HIV acquisition: a longitudinal study in Rakai, Uganda. AIDS 20, pp. 11911196.

Zuma, K., Gouws, E., Williams, B., \& Lurie, M. (2003). Risk factors for HIV infection among women in Carletonville, South Africa: migration, demography and sexually transmitted diseases.International Journal of STD and AIDS, 14(12): 814-817. 
Table 1: Description of the focus groups and participants in the study

\begin{tabular}{|c|c|c|}
\hline Focus group type & $\begin{array}{l}\text { Number and gender of the } \\
\text { participants }\end{array}$ & $\begin{array}{l}\text { Number of years the participants had } \\
\text { lived in the mining town }\end{array}$ \\
\hline Mineworkers & 7 (5 men; 2 women) & $\begin{array}{l}15+\text { years }(n=2) \\
5-10 \text { years }(n=1) \\
<5 \text { years }(n=4) \\
\text { Range } 2-16 \text { years }\end{array}$ \\
\hline Foreman and supervisors & 7 men & $\begin{array}{l}25+\text { years }(n=5) \\
10-20 \text { years }(n=4) \\
\text { Range 10-34 years }\end{array}$ \\
\hline $\begin{array}{l}\text { Mineworkers who'd received } \\
\text { treatment for substance abuse }\end{array}$ & 9 (8 men; 1 woman) & $\begin{array}{l}20+\text { years }(n=5) \\
10-15 \text { years }(n=3) \\
2 \text { years }(n=1) \\
\text { Range } 2-29 \text { years }\end{array}$ \\
\hline Oshiwambo-speaking workers & 8 men & $\begin{array}{l}28 \text { years }(n=1) \\
10-20 \text { years }(n=4) \\
<5 \text { years }(n=3) \\
\text { Range } 3-30 \text { years }\end{array}$ \\
\hline Workers' spouses & 8 women & $\begin{array}{l}11 \text { years }(n=1) \\
5-10 \text { years }(n=5) \\
<5 \text { years }(n=2) \\
\text { Range } 1-11 \text { years }\end{array}$ \\
\hline Youths & 7 men & $\begin{array}{l}18+\text { years }(n=4) \\
13-18 \text { years }(n=3) \\
\text { Range 13-22 years }\end{array}$ \\
\hline Total & 46 (35 men; 11 women) & Range $2-34$ years \\
\hline
\end{tabular}

